\title{
A weird thumb infection in a child: Could it be herpes?
}

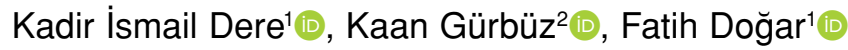 \\ 'Department of Orthopedics and Traumatology, Kahramanmaraş Sütçü Imam University Medical Faculty, Kahramanmaraş, Turkey \\ ${ }^{2}$ Department of Orthopedics and Traumatology, Kayseri City Training and Research Hospital, Kayseri, Turkey
}

Two serotypes of the herpes simplex virus (HSV) have been identified that can infect any cutaneous site of the body. While HSV-1 most commonly causes gingivostomatitis and a subsequent recurrent labial herpes, ${ }^{[1]}$ HSV-2 is most frequently associated with genital herpes. ${ }^{[2]}$ Both infections are common, and almost all of their clinical presentations are well established. However, the clinical presentation of HSV infections of the hand is less well-described and less known in adults and even lesser-known in the pediatric age group.

Since the first HSV infection in the hand was described in 1909, it has been published in the literature only rarely due to it being a low-frequency infection. ${ }^{[3,4]}$ However, considering the frequency with which children use their own hands to explore the world, including their mouths and the mouths of other individuals and animals, hand infection can be expected to be more common among children.

Received: November 21, 2021

Accepted: January 16, 2022

Published online: February 10, 2022

Correspondence: Kadir İsmail Dere, MD. Kahramanmaraş Sütçü Imam Üniversitesi Tıp Fakültesi Ortopedi ve Travmatoloji Anabilim Dalı, 46040 Onikişubat, Kahramanmaraş, Türkiye.

E-mail: kaisder46dr@hotmail.com

Doi: $10.52312 /$ jdrscr.2022.35

Citation: Dere Kl, Gürbüz K, Doğar F. A weird thumb infection in a child: Could it be herpes?. Jt Dis Relat Surg Case Rep 2022;1(2):43-46.

C2022 All right reserved by the Turkish Joint Diseases Foundation

This is an open access article under the terms of the Creative Commons Attribution-NonCommercial License, which permits use, distribution and reproduction in any medium, provided the original work is properly cited and is not used for commercial purposes (http://creativecommons.org/licenses/by-nc/4.0/).

https://www.casereportsjointdrs.org

\section{ABSTRACT}

Herpes simplex virus (HSV) has two known serotypes and can infect any cutaneous location of the body. Almost all HSV clinical symptoms are well known. Hand HSV infections are less well-known in adults and even less known in children. A three-year-old male child was hospitalized to a tertiary pediatric emergency room with growing swelling and discomfort in his thumb and a rare pediatric herpetic hand infection. His viral culture and pathology findings confirmed HSV infection. Inquisitiveness revealed the child's status as a thumb sucker. In conclusion, pediatric herpetic hand infections are rare and can be easily missed. Children with HSV infection without an underlying illness are self-limiting and respond well to medical treatment.

Keywords: Child, hand, herpes, infection.

Herein, we report a case of HSV-1 infection in the thumb of a child that was treated conservatively.

\section{CASE REPORT}

A three-year-old male child was admitted to a pediatric emergency department of a tertiary hospital with a progressive history of swelling and tenderness of the thumb with irritability to the child. There was no history of trauma and underlying diagnosed disease. His caregiver noticed a dark spot on the tip of the left thumb two days previously and took the child to her general practitioner, who prescribed nitrofurazone and pricked a blister with dressing. On the morning of the same day, when the mother pulled the dressing out, the blistering spread to involve the entire thumb. The tip of the thumb underwent superficial necrosis with the elevation of the epidermis and the distal portion of the nail from its bed. The thumb was swollen and erythematous and held in a semi-flexed position at the distal interphalangeal joint (Figure 1a).

After epidermal necrosis over the thumb debridement and the nail was excised under 

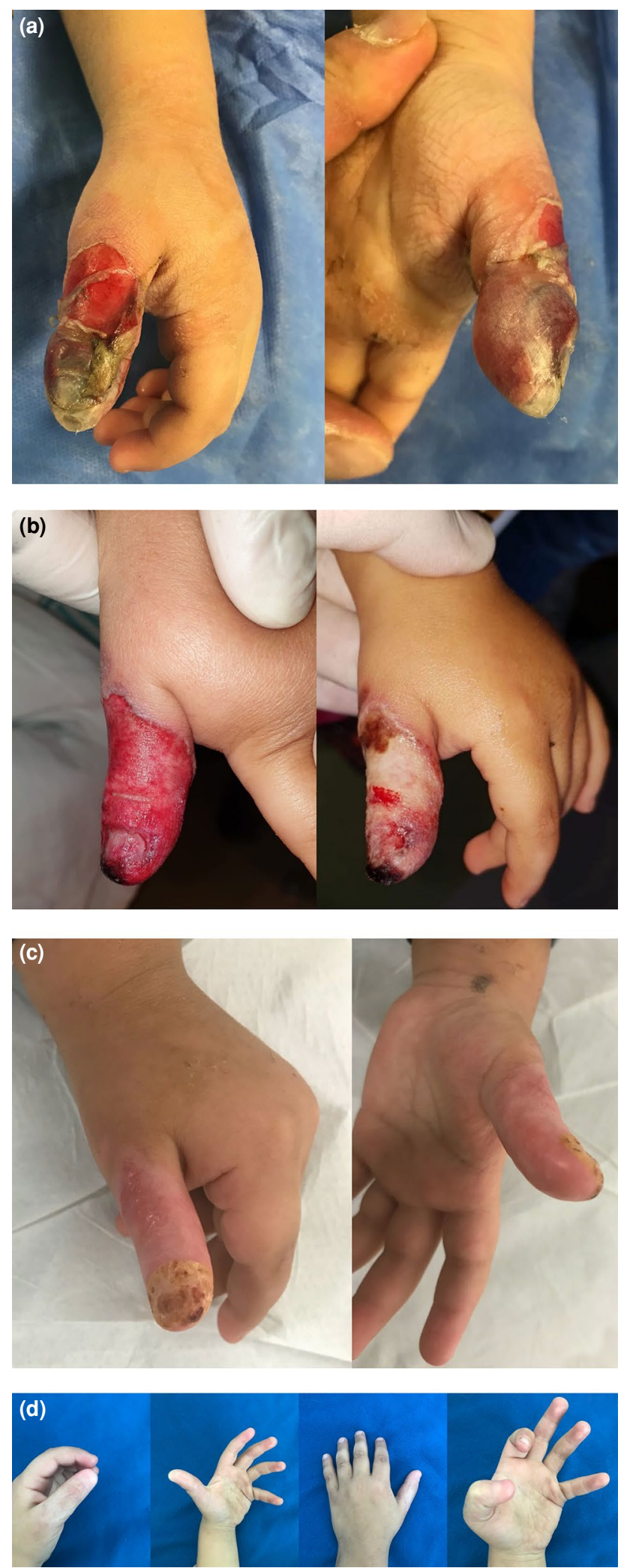

Figure 1. (a) Clinical presentation of infection on the thumb. (b) Sequential clinical views of the infection every three days in the first 10 days postoperatively. (c) The clinical view of the thumb just at the ends of the follow-up in the third month. (d) The final clinical view of the thump at the end of the first year. anesthesia sedation using aseptic precautions, the specimens were sent for microbiological and pathological examinations (Figure 2a-c). Addressing with local anesthetics was applied twice daily. Then, the patient was admitted to a pediatrics clinic and medically treated with ceftriaxone $(100 \mathrm{mg} / \mathrm{kg} /$ day $)$ under the consultation of pediatric infectious disease (Figure 1b). After four days of the operation, the child was diagnosed with herpetic gingivostomatitis, and the medical treatment was changed to acyclovir $(60 \mathrm{mg} / \mathrm{kg} /$ day). Addressing with local anesthetics was changed to acyclovir once daily for six days. Two days before the child was discharged, his viral culture and pathological results confirmed the diagnosis of HSV infection. Four weeks after the operation, at the final follow-up at our orthopedic outpatient clinic, the re-epithelization process was noted to be completed (Figure 1c-d).

Predisposing factors were considered, and, on close questioning of the child's caregiver, it became clear that the child was a thumb sucker.

The parents of the patient were informed that data from the case would be submitted for publication and gave their consent.

\section{DISCUSSION}

In case of pediatric herpes hand infection, the usual presenting symptoms include pain at the affected digit and irritability. After an incubation period of 7 to 20 days, erythema, swelling, and tenderness are followed by a vesicular eruption, often involving the digit. Fever, lymphadenopathy, and lymphangitis typically occur in primary cases. Multiple small vesicles enlarge and coalesce to form a large blaster, often leading to subsequent superficial necrosis. The turbid serous fluid released by the blasters can mimic pus was produced by possible bacterial infection. It is very unusual that the adjacent digit, as well as the palm, were involved, as described by Norris ${ }^{[5]}$ Over the next 10 days, gradual crusting and desquamation of the involved epidermis occurred, with the final re-epithelization occurring in three to four weeks. Other causes of palmar lesions include cellulitis, coxsackie viruses, erythema multiforme, sporotrichosis, impetigo, or trauma in the differential diagnosis. ${ }^{[6]}$

In infants, passive serological immunity acquired by the placental transmission of antibodies to HSV-1 and HSV-2 provides immunity against herpetic infection for the first six months of infancy. Once this placental transmitted immunity is over, the 


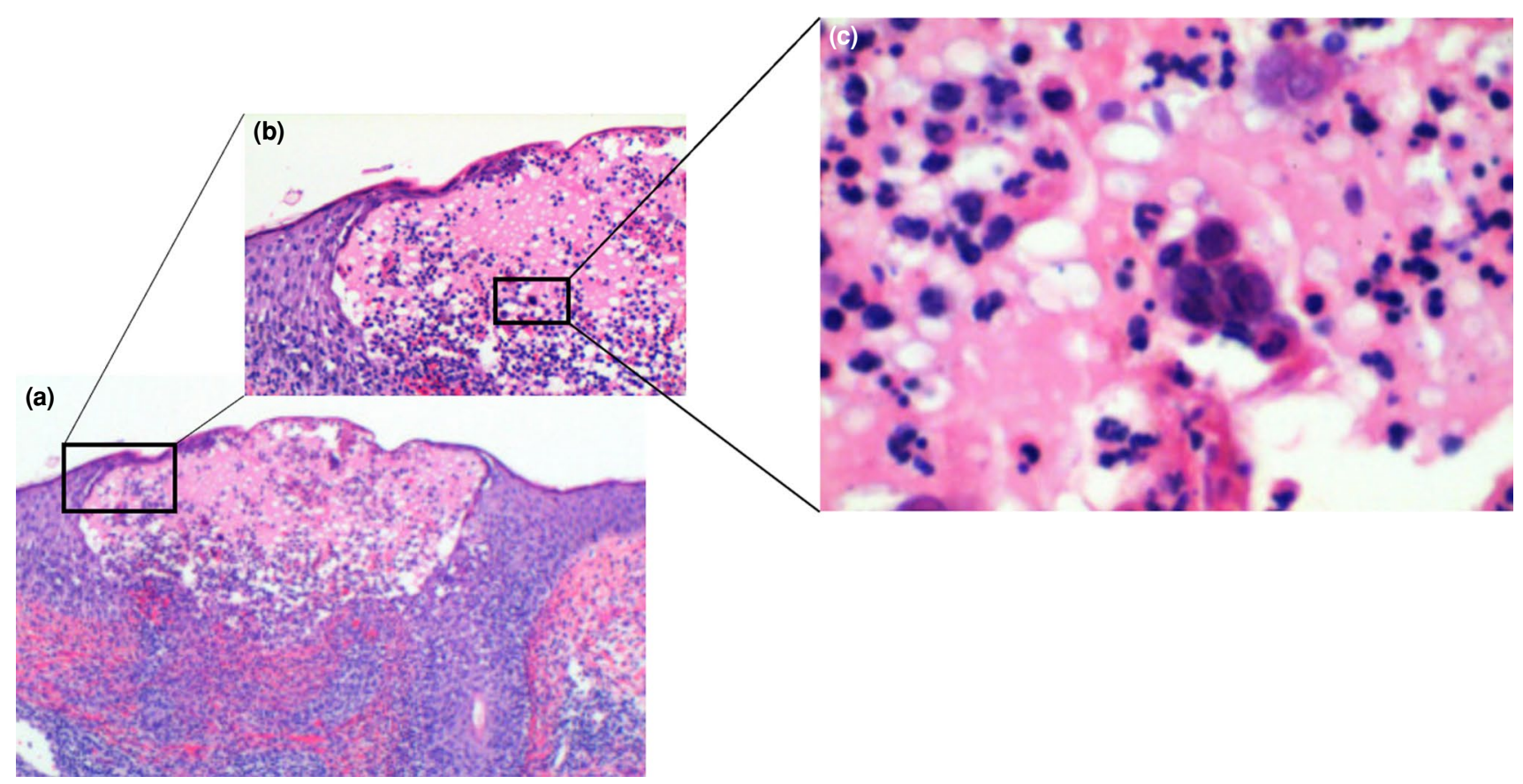

Figure 2. (a) Histopathological H-E-stained view of the intraepidermal blaster with acanthosis of the solitary keratinocytes within the blaster $(\times 4)$. (b) Keratinocytes show nuclear changes including migration of the nuclear chromatin, multinucleation and nuclear inclusions $(\times 10)$. (c) The HSV inclusions are small pink deposits with a clear halo seen within the nucleus, named Cowdry Type A inclusions in the literature $(\times 60)$.

infants are exposed to the virus via contact with infected peers and adults. Saliva and feces seem to be the major route of transmission in almost all cases. Active HSV has been detected in the saliva of $7 \%$ of individuals with no clinical manifestations. ${ }^{[7]}$ Thus, children of age six months to five years are not only susceptible to primary herpetic infections, but are also exposed to a large reservoir of this virus.

Pediatric herpes hand infection can develop by autoinoculation or exogenous origin. The habit of playfully sucking the fingers or toes of her babies of mothers or fathers with herpes labialis poses a risk for exogenous infection. ${ }^{[8]}$ The most important risk factor for infection by autoinoculation is thumb sucking and the thumb is most frequently affected..$^{[8,9]}$

Not only the differentiation of bacteria from herpetic hand infections, but also the recognition of bacterial contamination on viral infection needs to be performed meticulously. Deep incision and drainage of purely viral lesions can predispose to bacterial super-infection or accelerate the systemic dissemination of the virus. The latter can potentiate HSV meningoencephalitis, which has the highest known fatality rate among all viral causes of encephalitis. ${ }^{[4]}$ Therefore, incision and drainage are not recommended in pediatric herpes hand infections. ${ }^{[3,8,9]}$
In conclusion, not only orthopedic surgeons, but also clinicians should be aware of herpetic hand infection as a clinical entity. This case demonstrates two clinical pearls to conclude. First, pediatric herpetic hand infections are relatively uncommon and hence can be easily overlooked. Second, as herpetic hand infections in a child without any underlying disease is self-limiting and usually resolves with the proper medical treatment within three to four weeks, surgical intervention should be minimal. If performed, it should be aimed at decompression in the form of dermal necrosis debridement. Deep structures should never be incised, unless an abscess formation exists due to bacterial infection.

\section{Declaration of conflicting interests}

The authors declared no conflicts of interest with respect to the authorship and/or publication of this article.

\section{Funding}

The authors received no financial support for the research and/or authorship of this article.

\section{REFERENCES}

1. Özdemir Ö, Karavaizoğlu Ç, Büyükavcı M. Süt çocuğunda pnömoniyle seyreden herpes simplex virüs. Sakarya Medical Journal 2016;6:249-53.

2. Cunningham AL, Taylor R, Taylor J, Marks C, Shaw J, Mindel A. Prevalence of infection with herpes simplex virus 
types 1 and 2 in Australia: A nationwide population based survey. Sex Transm Infect 2006;82:164-8.

3. Adamson HG. Herpes febrilis attacking the fingers. Br J Dermatol 1909;21:323-4.

4. Walker LG, Simmons BP, Lovallo JL. Pediatric herpetic hand infections. J Hand Surg Am 1990;15:176-80.

5. Norris RW. An unusual hand infection in a child--remember herpes! J Hand Surg Br 1985;10:267-8.

6. Rubright JH, Shafritz AB. The herpetic whitlow. J Hand Surg Am 2011;36:340-2.
7. Yap T, Khor S, Kim JS, Kim J, Kim SY, Kern JS, et al. Intraoral human herpes viruses detectable by PCR in majority of patients. Oral Dis 2021;27:378-87.

8. Szinnai G, Schaad UB, Heininger U. Multiple herpetic whitlow lesions in a 4-year-old girl: Case report and review of the literature. Eur J Pediatr 2001;160:528-33.

9. Lieberman L, Castro D, Bhatt A, Guyer F. Case report: Palmar herpetic whitlow and forearm lymphangitis in a 10-year-old female. BMC Pediatr 2019;19:450. 